\title{
Perspectivismo, Yuxtaposición y Contraste en El Señor Presidente
}

Como ha señalado Claudio Guillén, el perspectivismo es un concepto que cuenta con una larga tradición en las artes plásticas, en la filosofia y en la literatura. ${ }^{1}$ El primer párrafo de El Señor Presidente no sólo ubica dicha novela dentro de esa tradición, sino que además fija una de las imágenes claves que va a regir la concepción de la realidad en toda la obra. ${ }^{2}$ El rumor de las campanas que da comienzo a la novela llama la atención a un "maldoblestar de la luz en la sombra, de la sombra en la luz" (p. 7).$^{3}$ En un sentido literal, esta imagen anota la importancia

\pm "On the Concept and Metaphor of Perspective," en Comparatists at work. Studies in Comparative Literature, ed. Stephen G. Nichols, Jr. y Richard B. Vowles (Waltham, Toronto, London, 1968), pp. 28-90. Para un examen del perspectivismo en la literatura española, véase, además de la bibliografía que glosa Guillén, el libro de Mariano Baquero-Goyanes, Perspectivismo y contraste. De Cadalso a Pérez de Ayala (Madrid, 1963). Sobre el perspectivismo en general, consúltese el estudio de Charles I. Glicksberg, Modern Literary Perspectivism (Dallas, 1970).

2 Varios criticos, por diferentes razones, han señalado la importancia de esta imagen y de una segunda a que se llama la atención en el siguiente párrafo. Véase los estudios de Enrique Arenas-Capiello, Richard Jerome Callan, Richard L. Franklin, A. F. de Gaztambide, T. B. Irving, Yvette Jiménez de Báez, Seymour Menton y Ricardo Navas-Ruiz, fichas 810, 889, 1943, 516, 1124, 1130, 423 y 1240, 475, respectivamente, según la bibliografía recopilada por Pedro F. de Andrea, "Miguel Angel Asturias. Anticipo bibliográfico," Revista Iberoamericana, XXV (enero-abril, 1969), 133-267. También Jean Franco, An Introduction to Spanish American Literature (London, 1969), pp. 311-313, y Gerald Martin, "El Señor Presidente and How to Read It," Bulletin of Hispanic Studies, XLVII (1970), 223-243, han apuntado la importancia de estas imágenes. Este último es quien mejor las ha estudiado. Martin ve, correctamente, planteado en estas dos imágenes "the problem of truth," p. 236. Sin desmentir esta tesis, aqui interesan las dos imágenes en cuestión para destacar los procedimientos técnicos de Asturias - la perspectiva, la yuxtaposición y el contraste. También interesa observar que en cada ocasión en que el autor yuxtapone diferentes planos de la realidad, invariablemente lo hace con un propósito ético y desde "una" perspectiva moral.

${ }_{3}$ Miguel Angel Asturias, El Señor Presidente, 9a. ed., Losada, Buenos Aires, 1968. A esta edición se refieren las páginas que sẹ indiçan entre paréntesis des. pués de cada cita, 
que la luz y la sombra tienen en la organización de la narrativa. ${ }^{4}$ Dentro de un contexto más amplio, esta imagen subraya una realidad en la que los valores simbólicos - verdad-ficción-, sugeridos por la luz y la sombra, aparecen yuxtapuestos e invertidos.

El significado de esta imagen se intensifica y se hace más explícito unas páginas después, cuando la vida humana aparece descrita como una aleación de mentira y verdad en la que estos valores, una vez más, sin excluirse, contrastan. La vida dota a los seres humanos con "un ojo de vidrio y un ojo de verdad: los que ven con mi ojo de vidrio ven porque sueñan, los que ven con mi ojo de verdad ven porque miran! ¡Soy la vida, la Manzana-Rosa del Ave del Paraíso; soy la mentira de todas las cosas reales, la realidad de todas las ficciones!" (p. 24.25).

Si se toman las dos imágenes en cuestión y se las estudia en la totalidad de la obra, se verifica que la yuxtaposición de perspectivas y las oposiciones no sólo se constituyen en una metáfora fundamental para entender el diseño y el sentido de la novela, sino que al mismo tiempo revelan la esencia del procedimiento metafórico de Asturias en El Señor Presidente. La técnica consiste en enfocar el mundo de la dictadura desde más de un punto de vista. Dentro de este esquema, la función del lector es reconocer, por medio de asociaciones, las correspondencias y divergencias que existen entre los diferentes planos de la realidad. Esto se evidencia en la natrativa no únicamente al nivel de la estructura, sino también al nivel de los personajes y al del lenguaje.

La primera parte de $E l$ Señor Presidente termina con el capítulo titulado "El rapto". Este capítulo, después de presentar los detalles del plan de fuga del general Canales y los preparativos del rapto de su hija, Camila, concluye con el saqueo de la casa de aquél y con un violento "barretazo" que Vásquez le pega a "la Chabelona", nana de Camila: "Vásquez la calló de un barretazo" (p. 75). La acción cronológica no se reasume hasta varias páginas después, en el siguiente capítulo. Vásquez,

4 Seymour Menton, "La novela experimental y la república comprensiva de Hispanoamérica: Estudio analítico y comparativo de Nostromo, Le Dictateur, Tirano Banderas y El Señor Presidente," reimpreso en La novela Hispanoameri. cana, ed. Juan Loveluck (Santiago, Chile, 1969), pp. 230-276, ha llamado la atención a la importancia de la luz y la sombra en la novela. Véase en particulat las páginas 267-268. También se ha fijado en este aspecto de la obra Enrique Arenas-Capiello, "El Señor Presidente o la concepción demoníaca del mundo," Anuario de Filologia, VI-VII: 6-7 (Maracaibo, 1967.1968), 231-300. 
todavía armado de la barreta, está haciéndole una señal a Miguel Cara de Angel para trasladar a Camila de la casa de ella a "El Tus.Tep", el "fondín de mala muerte" donde éste va a esconderla: "Vásquez salió a la calle armado todavia - la barréa que le sirvió para callar a la 'Chabelona' era arma contundente-, y a una señal de su cabeza, asomó Cara de Angel con la hija del general en los brazos. La policía empezaba a huir con el botín cuando aquéllos desaparecieron por la puerta de 'El Tus-Tep'... La fondera esperaba... con la tranca en la mano para acuñar luego la puerta" (pp. 82-83).

Al entrar en "El Tus-Tep", Camila se da cuenta de que se halla dentro de un cuchitril en penumbra: "Por precaución no se encendió la luz eléctrica y seguía como única luz en la estancia la candela of recida a la Virgen de Chiquinquirá" (p. 73). Estas circunstancias estimulan en el lector una seric de asociaciones con incidentes del pasado de Camila que ya habían sido narrados en las primeras páginas del capítulo. En efecto, estos incidentes, como bien ha indicado Menton, representan un "retroceso cronológico" con referencia al capítulo anterior, pero no coincidimos con las razones que el crítico ha of recido como justificación para este particular. ${ }^{5} \mathrm{La}$ intención de Asturias, al empleat este salto retrospectivo en el tiempo, no es otra que hacer ver por medio de un montaje de situaciones análogas el cambio radical que ha tenido lugar en la vida de la joven. ${ }^{6}$ La alteración de la cronología responde a una concienzuda técnica en la que la perspectiva y el contraste tienen un papel funda. mental. Como se verá, estos dos factores hacen de este capítulo uno de los más artísticamente logrados de la novela y, además, un paradigma para estudiar la técnica narrativa del autor.

El capítulo empieza con una serie de sosegadas escenas de la vida de Camila a la edad de quince años que contrastan drásticamente, como ya se indicó, con las páginas finales del capítulo anterior. Se ve a la muchacha entreteniéndose los domingos por la tarde mirando un álbum fa-

5 Menton dice: "Este retroceso está en una posición anómala que, al parecer, interrumpe sin razón el relato del rapto que se completa al final del capítulo. El capítulo parece estar compuesto de dos escenas independientes sin más nexo que Camila, protagonista de las dos. Sólo más adelante se reconoce la importancia del retroceso en la construcción de la novela, en los capítulos quince y dieciocho, que señalan la ingratitud egoista de los tíos." (p. 270).

6 Aquí coincidimos con la opinión de Ricardo Navas-Ruiz, Literatura y compromiso. Ensayos sobre la novela politica bispanoamericana (São Paulo, 1962?), p. 107, quien explica la transición temporal como un recurso del que se sirve Asturias para "hacer vivir al lector el brutal salto que Camila va a dar o acaba de dar desde una dichosa pubertad a un desgraciada mayoría de edad." Ni Navas. Ruiz ni Menton, véase la nota cinco, han observado que lo que dilucida el pasaje en cuestión es la técnica básicamente cinematográfica, o lo que aquí se denomina "montaje de situaciones análogas." 
miliar de viejas fotografías. Este álbum, especie de cuadro dentro de un cuadro más amplio, tiene la intención de hacer recalcar el paso del tiempo, al contrastar las jóvenes figuras que aparecen en las páginas del álbum con los dobles de las mismas, trasmutados ya por el tiempo, que se pasean por la calle frente al balcón de la casa de Camila. El cambio repentino en la perspectiva temporal fija el tema central de este capítulo: "bien dicen que el tiempo pasa sobre la gente" (p. 79).

El cinematógrafo por definición consiste en la proyección consecutiva de imágenes fotográficas que vistas en sucesión crean la ilusión de movimiento. La rápida yuxtaposición del álbum familiar con "el álbum" de la calle produce ese efecto. El resultado es que Camila, por medio del cambio de enfoques, experimenta el mundo en metamorfosis. La sensación de movimiento provocada por las fotografías sirve como motivo de transición a la primera experiencia que Camila tuvo del mar:" "La inmensidad en movimiento. Ella en movimiento. Todo lo que en ella estaba inmóvil en movimiento. Jugaron palabras de sorpresa en sus labios al ver el mar por primera vez" (p. 79). La relación entre el álbum de fotografías, el mar y el cincmatógrafo queda claramente establecida en el siguiente pasaje:

el mar se parece a los retratos que salen en las vistas de viajes, sólo que en más grande.

Camila había oído hablar de las vistas de movimiento que daban a la vuelta del Portal del Señor, en las Cien Puertas, pero no sabía ni tenía idea de cómo eran. Sin embargo, con lo dicho por su primo, fácil le fue imaginárselas entornando los ojos y viendo el mar. Todo en movimiento. Nada estable. Retratos y retratos confundiéndose, revolviéndose, saltando en pedazos para formar una visión fugaz a cada instante, en un estado que no era sólido, ni líquido, ni gaseoso, sino el estado en que la vida está en el mar. (p. 80).

Al volver a la capital, Camila consigue it a "las vistas". Este hecho par. ticular llega a ser clave en el capítulo que se está discutiendo, pues está profundamente relacionado con la crisis actual de la muchacha.

De esa primera visita al cine hay tres aspectos que aquí importan.

7 Para una discusión sobre la importancia y la función de los motivos en la literatura, véase: Robert Humphrey, Stream of Consciousness in the Modern Novel (Berkeley and Los Angeles, 1968), pp. 49-56; Boris Tomashevsky, "Thematics," en Russian Formalist Cristicism. Four" Essays, traducción y notas por Lee $T$, Lemon y Marion J. Rẹis (Lincoln, Nebraska, 1969), pp. 61-95: 
Uno es la relación que la mezcla de la luz de la pantalla con la oscuridad de la sala de espectadores suscita en Camila. Otro es que la joven sale del cine con "los ojos llorosos" (p. 82). Y el tercero es la precipitada manera en que ella y el público salen del cinematógrafo: "Y como aquella vez del escondite, así salió de las vistas, ... atropelladamente, entre los que abandonaban las sillas y corrían hacia las puertas en la oscuridad. No pararon hasta el Portal del Comercio. Y alli supo Camila que el público había salido huyendo de la excomunión. En la pantalla, una mujer de traje pegado al cuerpo y un hombre mechudo de bigote y corbata de artista, bailaban el tango argentino" (p. 82).

Todo esto por sí solo no tendría ningún significado a menos que se tenga presente que este suceso de la vida de Camila sugiere otro semejante de su niñez. Dentro del cine, Camila tiene la sensación de hallarse en el cuarto del tragaluz donde en una ocasión, niña todavía, jugó al "tuero", a las escondidas. La peculiar mezcla de luz y sombra de este sitio tiene evidentes correspondencias con la experiencia en la sala de cine:

A Camila se le hizo tan precioso el recuerdo de una vez que se escondió con un muchacho en el cuarto del tragaluz, que se olvidó de las vistas. El candil de las ánimas moqueaba en el rincón más tenebroso de la estancia, frente a un Cristo de celuloide casi transparente. Se escondieron bajo una cama... "iTuero!", gritaron en el primer patio... Al oír los pasos del que buscaba diciendo a voces: "Voy con tamaño cuero!", Camila empezó a quererse reír. Su compañero de escondite la miraba fijamente, amenazándola para que se callara... pero no aguantó la risa... y habría soltado la carcajada si no se le llenan los ojos de una arenita que se le fue haciendo agua al sentir en la cabeza el ardor de un coscorrón. (p. 82$)^{8}$

Aquí cabe preguntarse ¿por qué ha insistido Asturias en la yuxtaposición del álbum de fotografías, del mar, del cine y ahora del juego a las escondidas en el cuarto del tragaluz? Para responder, hay que tener en cuenta la situación en que se encuentra Camila, sus circunstancias en "El Tus-Tep" inmediatamente después del rapto. Sólo si el lector tiene esto presente logra adosar todas las imágenes dentro de una sola, que confiere la unidad a este capítulo. Como se verá, esta asociación de imá.

8 Importa destacar que este juego al "tuero" se asocia y contrasta con la visión de la Chabelona, después del saqueo de la casa de Canales, gritando como fantasma con el cráneo rotọ: "-iTuero! ¡Tuero! iTurro!" (p. 87), 
genes informa toda la novela y se constituye en una característica fundamental de la técnica de Asturias.

Conforme quedó establecido, al ser trasladada de su casa a "El Tus. Tep", Camila es introducida en un mundo de sombra y luz análogo al del cuarto del tragaluz y al de la sala de cine:

El favorito fijaba los ojos, alternativamente, en la hija del general y en la llama de la candela ofrecida a la Virgen de Chiquinquirá. El pensamiento de apagat la luz y hacer una que no sirve le negreaba en las pupilas. Un soplido y. . . suya por la razón o la fuerza. Pero trajo las pupilas de la imagen de la Virgen a la figura de Camila caída en el asiento $y$, al verle la cara pálida bajo las lágrí. mas granudas, el cabello en desorden y el cuerpo de ángel a medio hacer, cambió el gesto, le quitó la taza de la mano con un aire paternal y se dijo:" "ipobrecita!" (p. 84).

La semejanza en la ofganización de los tres acontecimientos es evidente. En los tres Camila se halla en el interior de una estancia en que coincide la mezcla de la sombra con la luz: sala de cine, un cuarto con tragaluz, un fondín en penumbra. En los tres figuran el llanto y la fuga precipitada. En Jos tres, en una forma u otra, la religión, patente en el Cristo de celuloide, en la excomunión y en la Virgen de Chiquinquirá, está presente. ${ }^{9}$

La asociación de las tres situaciones análogas produce el contraste. En la experiencia de la niñez, esconderse en un lugar oscuro con lampos de luz, llorar y huir, eran parte de un juego, pura fantasía. El cine, a su vez, es un sitio donde se va principalmente por gusto. Pero el cuchitril - especie de catacumba - es parte de una realidad horrorosa que se contrapone, no obstante los paralelos señalados, a las otras dos. El cotejo simultáneo de estos tres lugares-símbolos no sólo pone en perspectiva lo abominable de la dictadura, sino que al mismo tiempo subraya el cambio radical que ha tenido lugar en la vida de Camila. ${ }^{10}$ Estas tres

9 Es interesante observar cómo se revela "la religión" en cada uno de estos tres casos. En la experiencia de la niñez, en el cuarto del tragaluz, la figura de Cristo no pasa de ser un juguete. El material, celuloide, de que está hecha la imagen así parece sugerirlo. En el episodio del cine la religión se presenta en forma opuesta a lo que se proyecta en la pantalla por ser ésta una especie de ojo a otra realidad que la que auspicia la iglesia. Finalmente, en el cuchitril, la Virgen de Chiquinquirá carece por completo de valor. Camila se salva de ser violada porque así lo decide Cara de Angel y no debido a la "intervención" de la Virgen. Del contraste de los tres incidentes, se concluye que la iglesia no tiene ningún significado, salvo, eso sí como una fuerza negativa que se opone al cambio.

10 Si ampliamos el significado de los tres "lugares-símbolos" en cuestión, se puede decir que toda la novela, toda la dictadura, es análoga al cuarto con tragav 
experiencias se unen con la del álbum de fotografías y la del mar en una sola metáfora para producir la sensación de cambio. El montaje de las imágenes establece la diferencia entre lo que Camila fue y lo que es, entre su pasado y su presente, entre la verdad y la ficción.

\section{III}

El motivo del cinematógrafo reaparece en la novela. Aunque la forma es otra, el procedimiento es básicamente el mismo: yuxtaponer perspec. tivas contrastantes de la realidad. En el capítulo XVI, Fedina de Rodas se halla en la cárcel por haber querido prevenir al general Canales que hay una orden de captura contra él por supuesto asesinato a "el hombre de la mulita". Junto a la visión de Fedina encarcelada, el narrador interpola otros planos de la realidad. Fuera de la cárcel se está celebrando un día de fiesta en honor del Señor Presidente:

En la ciudad continuaba la fiesta en honor del Presidente de la República. En la Plaza Central, se alzaba por las noches la clásica manta de las vistas a manera de patíbulo, y exhibíanse fragmentos de películas borrosas a los ojos de una multitud devota que parecia asistir a un auto de fe. Los edificios públicos se destacaban iluminados en el fondo del cielo. Como turbante se enrollaba un tropel de pasos alrededor del parque de forma circular, rodeado de una verja de agudísimas puntas. Lo mejor de la sociedad, reunido allí, daba vueltas y vueltas en las noches de fiesta, mientras la gente del pueblo presenciaba aquel cinematógrafo, bajo las estrellas, con religioso silencio. Un sardinero de viejos y viejas, de lisiados y matrimonios que ya no disimulaban el fastidio, bostezo y bostezo, seguían desde los bancos y escaños del jardín a los paseantes, que no dejaban muchacha sin piropo ni amigo sin saludo. (pp. 109 . $110)$.

Como el texto revela, la ciudadanía se halla congregada en la Plaza Central. Un grupo, "lo mejor de la sociedad", se dedica a dar interminables vueltas alrededor del parque. Otro, los pobres del pueblo, asiste, como "a un auto de fe", a un espectáculo que consiste en "fragmentos de películas borrosas" que están siendo proyectados al aire libre. Un ter.

luz, a la sala de cine y al cuchitril en penumbra. Cara de Angel, por ejemplo, entre los muchos encarcelados que aparecen en la novela, está metido en un calabozo donde recibe "dos horas de luz [y] veintidós horas de oscuridad". (p. 282). 
cer grupo, compuesto de "viejos y viejas, de lisiados y matrimonios que no disimulan el fastidio", mata el aburrimiento reparando en "el espectáculo" - los piropos y saludos- que los que se pasean alrededor del porque representan. Se trata, fundamentalmente, pues, de una represen. tación dentro de otra. El desdoblamiento de perspectivas y las correspondientes asociaciones rigen toda la descripción de este trozo y de todo el capitulo.

Aristóteles ha establecido que se produce una analogía "when there are four terms such that the relation between the second and the first is similar to that between the fourth and the third. For instead of the second the poet expresses the fourth, and instead of the fourth the second" (Poetics, 1457b). ${ }^{11}$ Tomando esta premisa como base, se puede insistir en que la analogía es el elemento fundamental del método de Asturias en El Señor Presidente. Por obra de la analogía, como era de esperar, se producen la imagen y el símbolo en la novela. Asturias emplea las correspondencias para hacer ver las conexiones que existen entre lo concreto y lo abstracto, entre la realidad visible y la realidad invisible de la dictadura. El procedimiento consiste en lo que Ezra Pound, al definir la imagen, llamaba la "unificación de ideas dispares" en un instante de tiempo. ${ }^{12}$

En tres ocasiones en este capítulo se alude a la manta o telón en que se está proyectando la película en el parque como a un patíbulo. En dos de ellas, Asturias se sirve de la misma correspondencia y casi de las mismas palabras: "la clásica manta de las vistas a manera de patíbulo" (pp. 109, 111). En la tercera referencia, la manta de las' vistas sustituye al patíbulo: "la manta de las vistas en lugar del patíbulo" (p. 111).

El desdoblamiento de la manta en patíbulo no es el único caso en el capítulo. Las personas que se pasean dando interminables vueltas alre. dedor del parque semejan -el lector así lo figura unas páginas después- a un grupo de esclavos atados a una noria: "la vuelta al parque de los esclavos atados a la noria" (pp. 111, 118). En esta última refe-

11 Para discusiones más detalladas sobre la analogía, véase: José FerraterMora, Diccionario de filosofia (Buenos Arres, 1951), pp. 53-55; William York Tindall, The Literary Symbol (Bloomington, 1962), pp. 28-67.

${ }_{12}$ Citado por René Wellek y Austin Warren, Teoría literaria, 4a. ed., prólogo de Dámaso Alonso, traducción por José M. Gimeno (Madrid, 1966), p. 223. Para una aplicación de la teoría de Pound a la literatura, véase: Joseph Frank, "Spatial Form in Modern Literature," reimpreso en The Widening Gyre. Crisis and Mastery in Modern Literature (Bloomington and London, 1968), pp. 3-62. Para una refutación de las conclusiones de Frank, consúltese Walter Sutton, "The Literary Image and the Reader," The Journal of Aestbetics and Art Criticism, XVI, 1 (1957-1958), 112-123, y William V. Spanos, "Modern Literary Crit. icism and Spatialization of Time: An Existential Critique," The Jonmal of Aestbetics and Art Criticism, XXIX, I (Fall, 1970), 87-104. 
rencia, las correspondencias - gente-esclavos, vueltas-noria- son efec. tuadas por el lector. Es decir que el lector es quien suministra el nexo, es él quien "crea" la metáfora.

Al examinar en detalle la descripción de la gente dando vueltas alrededor del parque, se comprneba que la forma de éste es circular y que además está "rodeado de una verja de agudísimas puntas" (p. 110). Ambos aspectos del parque adquieren importancia simbólica. Las innumerables vueltas que la gente da en el parque circular aluden metafórica. mente a una actividad cíclica, inacabable. De igual manera, el parque rodeado de una verja muy singular evoca una inevitable correspondencia con la cárcel.

El sentido de la analogía se fija si ahora, de nuevo, se vuelve la atención a Fedina en la prisión. Allí se la observa a ésta oyendo una monótona y presagiadora canción, diciendo una interminable letanía, contando las continuas vueltas del reloj que nada cambian y sintiendo morir en sus brazos a su hijo de pecho. Con esto y todo lo antes dicho en pers. pectiva, se establece que la fiesta de la ciudad representa más que un mero contraste con el "patíbulo" de Fedina. La fiesta se impone como un símbolo de toda la sociedad. El enmascaramiento manifiesto en el cambio de la manta de las vistas en patíbulo, de los paseantes del parque en esclavos, del parque en cárcel, sugiere un engaño fundamental que se extiende a toda la dictadura. La implicación es que la manta de las vistas, los paseantes y la verja del parque son espejos que rezuman la falsedad de la sociedad.

El mundo de la cárcel donde se halla Fedina, contrapuesto a la ciudad en fiesta, es análogo al patíbulo, a la noria y a la simbólica cárcel sugerida por la verja del parque, omnipresentes en la dictadura, aunque no siempre discernibles. La analogía, gráficamente representada, resulta la siguiente:

\begin{tabular}{|c|c|c|c|}
\hline Ciudad en fiesta: & Fedina en la cárcel & $\begin{array}{l}\text { Verja del } \\
\text { parque }\end{array}$ & $\begin{array}{l}\text { Cárcel } \\
\text { simbólica }\end{array}$ \\
\hline Ciudad en fiesta: & Fedina en la cárcel & $\begin{array}{l}\text { Manta de } \\
\text { las vistas }\end{array}$ & Patíbulo \\
\hline Ciudad & has & $\begin{array}{l}\text { Vueltas en } \\
\text { el parque }\end{array}$ & $\begin{array}{l}\text { Noria de } \\
\text { esclavos }\end{array}$ \\
\hline
\end{tabular}

Resulta claro que detrás del espectáculo público para celebrar al Señor Presidente se oculta un mundo aterrador que pasa inadvertido - un mundo en el que la esclavitud y el encarcelamiento están encubiertos por 
las apariencias. Al respecto, en el capítulo XXVIII, uno de los presos sintetiza este mundo así: "Y pensar que en la ciudad todo debe estar como si tal cosa, como si nada estuviera pasando, como si nosotros estuviéramos aquí encerrados. El tranvía debe seguir andando" (p. 198).

\section{IV}

Lo anterior, además de destacar la inclinación de Asturias hacia la yuxtaposición y contraste de perspectivas, sugiere que en esta sociedad hay una realidad pública y otra oculia. Un importante aspecto de esa realidad, quizás el mayor y el más revelador, permanece puertas adentro, en la oscuridad. Lo que se proyecta a la luz pública es la máscara, la representación; ésta sirve, particularmente bajo una dictadura, como una especie de protección y defensa:

La casa permite comer el pan en oculto --el pan comido en oculto es suave, enseña la sabiduría--; posee la seguridad de lo que permanece y apareja la consideración social, y es como retrato familiar, en el que el papá se esmera con el nudo de la combata, la mamá luce sus mejores joyas y los niños están peinados con "Agua Flo. rida" legítima. No así la calle, mundo de inestabilidades, peligroso, aventurado, falso como los espejos, lavadero público de suciedades de vecindario. (p. 127).

El mundo abierto y el mundo cerrado, al cual llama la atención el texto anterior, se despliega a todos los niveles de la novela de diferentes maneras. Los miembros del régimen esconden su verdadero carácter de trás de diversos disfraces. Así ocurre, por ejemplo, con la dualidad que se observa en el Auditor de Guerra. Fedina Rodas, al ser encarcelada, recuerda que ha visto a este personaje cantando en el coro de la iglesia, por lo tanto espera de él un comportamiento en armonía con tal cargo: - “ $i$ Este es el señor que le loca el armonio a la Virgen del Carmen! $\rightarrow$ se dijo Niña Fedina-. Ya me parecía conocerle cuando me capturaton; lo he visto en la iglesia. ¡No debe ser mal hombre!" (p. 112). El lector que observa la escena desde otra perspectiva reconoce que la realidad del caso es otra.

Asimismo, Asturias llama la atención al doble punto de vista que existe en torno al Auditor de Guerra, por medio de una de esas alusiones que puede pasar desapercibida pero que, adecuadamente analizada, 
revela un contraste implícito en la personalidad del Auditor. Se da el caso de que en su escritorio este personaje ostenta una estatua de la diosa Themis, representante clásica de la justicia absoluta (p. 233). La aso. ciación de este símbolo con el Auditor de Guerra, personificación de la injusticia, hace hincapié en la discrepancia que existe entre el uno y el otro.

En ambos casos se trata de una impostura, de un enmascaramiento, que presume una dualidad de perspectivas. La máscara, como ha señalado Octavio Paz, supone una escisión fundamental entre lo que se es y lo que se simula. ${ }^{13}$ Una de las pretensiones de todo impostor, obviamente, es engañar a su público, fingirse otro. Este es sin duda el caso del Auditor de Guerra. Pero hay otras manifestaciones del enmascaramiento en El Señor Presidente. Tienen que ver con la ironía que circunda a todos aquéllos que bajo la dictadura se engañan, engañando el régimen.

A un nivel elemental esto se comprueba en cuanto a los espías, quienes a sla vez son espiados. El resultado es un cuadro en que interviene una doble perspectiva por medio de la cual burlador y burlado son recípro. camente reflexivos: "la cocinera que espía al amo y a la de adentro, y la de adentro que espía al amo y a la cocinera, me informan... (p. 66).

Es.e barroco juego de espejos convierte a la dictadura en un gran teatro en que los protagonistas son autores, actores, escenario y público - titiriteros y títeres al mismo tiempo. Cara de Angel, por ejemplo, cree poder librarse del control del régimen, no obstante el hecho de reconocer, en los primeros momentos de su "conversión", que su papel de siempre no ha sido otro que el de ser un "instrumento ciego", un títere, del Señor Presidente (p. 71). Cuando se le presenta la oportunidad de poder escapar de la dictadura, se engaña creyendo que ha tergiversado los papeles: "¿qué podrían adivinar? Hazme el favor: el que me manda a Wäshington es él [el señor Presidente]; él es el que me paga el viaje" (p. 262). La realidad del caso es otra. Se confirma la condición de fantoche de Cara de Angel cuando, a punto de embarcarse para su "libertad", es substituido por otra figura, por un doble suyo: "alto como Cara de Angel, pálido como Cara de Angel, medio tubio como Cara de Angel" (p. 268). Su muerte es asimismo parte de una comedia urdida por el Señor Presidente.

13 "Máscaras mexicanas," en El laberinto de la soledad, sa. ed., (México, 1967), pp. 26-41. 
La manipulación del destino de Cara de Angel, además de anotar la importancia del fingimiento, de lo teatral, en la dictadura, también llama la atención a una doble perspectiva en la que la mentira se propone como verdad. $^{\text {i4 }}$ Estos dos aspectos los ilustra de una manera más compleja el juicio contra el licenciado Carvajal. Valiéndose de una técnica que encaja dentro de lo grotesco, Asturias destaca lo teatral y la desproporción entre mentira y verdad que caracteriza la dictadura.

El número de opiniones tocante a lo grotesco es muy variado y se multiplica cada día debido a un renovado interés en esta categoría estética. ${ }^{15}$ No obstante, la mayoría de los críticos que se han ocupado de este fenómeno coinciden en que se trata de un sentimiento de incongruencia que se produce en el espectador como reacción ante la falta de concordancia entre el fenómeno deformado que éste contempla y la con. cepción que la convención le ha impuesto del mismo fenómeno. De esta manera, intervienen simultáneamente en el observador dos perspectivas de la realidad: la deformación y el orden, lo aterrador y lo cómico. Estas dos relaciones, entre otras que caracterizan lo grotesco, se aplican plenamente en el caso del juicio contra Carvajal.

El proceso tiene todas las características de una representación teatral grotesca. Carvajal, "el reo", desde cuya perspectiva se observa la situación, ve el proceso, muy significativamente, como "un sueño, mitad rito, mitad comedia bufa. El era el principal actor" (p. 207). Carvajal observa que una galería de goyescos mendigos, puestos allí por el miedo y controlados por "soldados dispuestos contra los muros a cada dos pasos en toda la sala", compone el grupo de testigos representantes del gobierno (p. 205). Carvajal percibe a los pordioseros como figuras deformes. Uno está descrito como "sholco", sin dientes. Otro tiene "la dig. nidad de un gorila". Una mirada de conjunto revela seres con narices aplastadas y encarnadas, con dientes granudos, con bocas que cuelgan de las orejas, con caras que recuerdan muecas de cadáveres, con barbas sucias de alimentos, con tacones torcidos. En el cuadro también aparecen

14 Carlos Navarro, "La desintegración social en El Señor Presidente," Revista Iberoamericana, XXXV, 67 (enero-abril, 1969), 59-76, ha llamado la atención sobre la importancia de la mentira en la dictadura.

15 Para una discusión de las diferentes opiniones sobre lo grotesco, véase: Michael Steig, "Defining the Grotesque: An Attempt at Synthesis," The Journal of Aestbetics and Art Criticism, XXYX, 2 (Winter, 1970), pp. 253-260. 
un enano, una sordomuda con el vientre abultado, un hombre con una sola oreja como bacinica y una mujer flaca, tuerta y bigotuda (p. 205).

Asturias amplía el efecto grotesco al presentar un tribunal que al igual que los testigos es asimismo una farsa. Los militares que lo integran se hallan en un caricaturesco estado de embriaguez, con lo que contribuyen a hacer del juicio una comedia al mismo tiempo risible y aterradora. Se trata, pues, de un simulacro de justicia, de una grotesca marioneta, cuyos hilos están siendo manejados desde lejos por el Señor Pre. sidente. ${ }^{16} \mathrm{La}$ intención grotesca de Asturias surge al contraponer la seriedad imponente de la sentencia emitida contra Carvajal con las ridículas figuras de los militares borrachos del tribunal, con las de los pordioserostestigos y con las de los "soldaditos" esparcidos por la sala:

La sentencia, redactada y escrita de antemano, tenía algo de inmenso junto a los simples ejecutores, junto a los que iban a echar el "fierro", muñecos de oro y de cecina, que bañaba de arriba abajo la diarrea del quinqué; junto a los pordioseros de ojo de sapo y sombra de culebra, que manchaba de lunas negras el piso naranja; junto a los soldaditos, que se chupaban el barbiquejo; junto a los muebles silenciosos, como los de las casas donde se ha cometido un delito. (p. 206).

Este teatro de fantoches - tremenda parodia de un proceso judicialestimula asociaciones con otro: el del titiritero del Portal. La asociación del juicio de Carvajal con el teatro de títeres de don Benjamín produce correspondencias y contrastes. En ambos "teatros" el procedimiento es similar, el injerto característico de lo grotesco. En el caso del teatro de títeres, la yuxtaposición de elementos humanos - llanto- con elementos mecánicos - - los títeres - destruye el orden convencional de las cosas y produce lo grotesco. La diferencia básica entre las dos "representaciones" reside en el hecho de que, en el caso del juicio de Carvajal, se trata de "verdaderas" personas representando una mentira, mientras que en el teatro de don Benjamín se pretende lo opuesto; por medio de muñecos, por medio de la ficción, éste intenta dar a conocer la verdad. $\mathrm{El}$ resultado es irónico.

Ocurre que después que don Benjamín y su mujer, doña Venjamón, presencian las últimas circunstancias del asesinato del Pelele, los muñecos

16 A propósito, en El Señor Presidente se dice lo siguiente: "Una red de hilos invisibles, más invisibles que los hilos del telégrafo, comunicaba cada hoja con el Señor Presidente, atento a lo que pasaba en las vísceras más secretas de los ciudadanos" ( $p .38$ ). 
del titiritero que "sólo habían reído" se aventuran por "los terrenos de la tragedia" (pp. 54-55). La interpretación de este incidente en el teatro de títeres paradójicamente, no tiene los resultados que espera don Ben. jamín. La representación, en vez de producir llanto, como él lo esperaba, produce risa en sus juveniles espectadores:"1z "Don Benjamín creyó que los niños lloratían con aquellas comedias picadas de un sentido de pena y su sorpresa no tuvo límites cuando los vio reír con más gana, a mandíbula batiente, con más alegtía que antes. Los niños reían de ver llorar... Los niños reían de ver pegar..." (p. 55). En ambos casos, en el juicio de Carvajal y en el teatro de títeres, el mundo aparece dislocado, se manifiesta al revés, patas arriba. En efecto, si se coteja el proceso de Carvajal con el teatro de don Benjamín, se recalca la intención ética de Asturias, al igual que la inversión de perspectivas anunciada por una de las dos imágenes claves ya glosadas: " $i$ Soy la vida. La Manzana-Rosa del Ave del Paraíso; soy la mentira de todas las cosas reales, la realidad de todas las ficciones!" (p. 25).

\section{VI}

Revelador de la yuxtaposición de perspectivas y de los contrastes a que Asturias recurre a menudo es el cambio de máscaras que se observa en el general Canales. Al salir éste de la casa de Cara de Angel, después de haber sido informado que hay una orden de captura contra él, su manera de caminar se manifiesta simultáneamente en la de una figura de paso marcial, digna de una "parada militar", y en la carrerita de un indio que "va al mercado a vender una gallina" (p. 62). La escisión que tiene lugar en la figura de Canales está vista desde el interior del perso. naje. El resultado es un collage de las diferentes impresiones que Canales tiene de sí mismo, después de haber perdido los favores del Señor Pre. sidente. En una escena entre cómica y trágica, el general se convierte en. un mero fantoche:

En el fondo de sí mismo se iba abriendo campo otro general Canales, un general Canales que avanzaba a paso de tortuga... El ver-

17 Una posible explicación de la risa de los niños se la encuentra en el libro de Lee Byron Jennings sobre lo grotesco, The Ludicrous Demon. Aspects of the Grotesque in German Post-Romantic Prose (Berkeley and Los Angeles, 1963), p. 12. Para este crítico cuando se ve algo en un escenario, en este caso los títeres, por tratarse de algo que de antemano se reconoce como ficción, "the monstrosity is removed... and the basic attitude" del espectador es "characterized by amusement." 
dadero "Chamarriı", el Canales que había salido de casa de Cara de Angel arrogante, en el apogeo de su carrera militar... veíase sustituido de improviso por una caricatura de general... El descharchado general Canales avanzaba a la hora de una derrota que no conocería la historia, adelantándose al verdadero, al que se iba quedando atrás como fantoche en un baño de oro y azul, el tricornio sobre los ojos, la espada rota, los puños de fuera y en el pecho enmohecidas cruces y medallas. (pp. 63-64).

El narrador le advierte inmediatamente al lector, por medio de contrastes, "la importancia" que Canales asigna a la pérdida del poder: "Le acongojaba verse en el destierro con un pantalón de portero y una americana, larga o corta, estrecha u holgada, jamás a su medida" (p. 64). Este último pasaje tiene al mismo tiempo una importancia estética y ética. En primer término, sugiere un paralelo con otro incidente de la novela. Los pensamientos de Canales suscitan correspondencias con los del Señor Presidente cuando éste recuerda aspectos de su vida antes de llegar al poder: "Se vio empequeñecido en el hoyo de sus coterráneos, aislado de todo... Y se vio más tarde en su oficina de abogado de tercera clase, entre marraneras, jugadores, cholojeras, cuatreros, visto de menos por sus colegas que seguían pleitos de campanillas"' (p. 223). En segundo lugar, al comentar sobre Canales en términos de lo que el poder significa para él y luego asociar los pensamientos de éste con similares preocupaciones del Señor Presidente, Asturias hace de Canales un ser despreciable, déspota en potencia, conmovido por el amor al poder más que por ningún principio ético o social. Esta asociación anticipa y prepara la opinión del lector en cuanto a Canales, "líder revoluciona. rio". Resulta contraproducente e inaceptable que un general de la milicia del Señor Presidente se convierta vertiginosamente en un revolucionario sincero.

\section{VII}

El doble punto de mira, las asociaciones y los contrastes, también se los encuentra en el capítulo "Luz para ciegos". El oxímoron implí. cito en el título ya indica un enfrentamiento de perspectivas opuestas, al revés. Se trata de una escena en la que lo bucólico se manifiesta yuxtapuesto y en evidente contraste con lo satánico. Por un lado se hallan los esposos Camila y Cara de Angel, por el otro aparece "una culebra color de mariposa: 'La Siguemonta"" (p. 238). Esta serpiente está des. 
crita como un "espíritu raro" que ronda los baños donde se encuentran los dos idílicos amantes. Luego de informar al lector acerca de este particular, Asturias comienza a tejer poco a poco esta imagen del mal.

Por primera vez, simbólicamente, este espíritu maligno se revela en la forma apropiada de un gusano - por asociación, una culebra en mi. niatura e igualmente una mariposa en potencia - para causarle terror a Camila: "Camila sintió un gusano en la toalla... Sentirlo, gritar, venir Cara de Angel y acabar con el '...sano, todo fue uno" (p. 239). Salvar a Camila de este trance cor el gusano es un simulacro irónico de lo que ocurrirá después. Sucede que Cara de Angel no podrá librar a Camila de la serpiente alegórica, de las fuerzas del mal concentradas en el Señor Presidente. Esta imagen se clarifica en el siguiente capítulo, donde se sugiere que Cara de Angel, ciego, deslumbrado por el amor, no se ha percatado de que su felicidad está siendo acechada por las simbólicas serpientes: "Pero las serpientes estudiaron el caso. Si el azar no los hubiera juntado, ¿serían dichosos?.. Se sacó a licitación pública en las tinieblas la demolición del inútil encanto del Paraíso y empezó el acecho de las sombras, vacuna de culpa húmeda, a enraizar en la voz vaga de las dudas y el calendario a tejer telerañas en las esquinas del tiempo" (p. 241).

La yuxtaposición de perspectivas también se halla en torno a las prostitutas de "El Dulce Encanto". La base del contraste aquí surge de la aparente paradoja que resulta de la asociación de un sentimiento religioso o un sentimiento de maternidad con la prostitución o, mejor, con la opinión ortodoxa de esta ocupación (pp. 109, 153, 164-165). De igual intención es la humorística referencia a tres grotescas prostitutas como a las míticas "tres gracias" (p. 149, 155). El entrecruzamiento de dos mundos que no coinciden es ejemplificado también por medio de la mezcla de lo vulgar con lo excelso. En un burdel de mala muerte, frente al cual había llegado Cara de Angel buscando al mayor Farfán para prevenirlo de que su vida corría peligro, alguien toca el "Claro de Luna" de Beethoven (p. 175).18 Cabe hacer hincapié en el hecho de que, en cada caso, de los muchos ejemplos que se podrían glosar, la polaridad de perspectivas llama la atención, por medio de contrastes, a una realidad que necesita ser corregida.

18 El número de ejemplos en que intervienen la yuxtaposición de perspectivas y los contrastes abundan en la novela. Interesantes son las escenas en que se mezcla lo onírico con lo real. Respecto a esto, Enrique Arenas-Capiello, pp. 248-255, ha indicado la pauta señalando "el elemento onírico y algunos recursos surrealistas" de la novela. 


\section{VIII}

La mayoría de los recursos técnicos hasta aquí estudiados se manifiestan también al nivel del estilo propiamente dicho. Ya es proverbial repetir que a Asturias le gusta jugar con las palabras. Sin embargo, importa destacar que "el juego", en un buen número de los casos, tiene una función metafórica. Valiéndose de la paranomasia y los juegos de palabras, Asturias lleva a cabo la unión de dos niveles de significados dentro de una sola experiencia. Este es el caso de ejemplos tan repetidos como el de "Lucio Vásquez", que se convierte en "Sucio" y "Bascas" respectivamente. De igual intención es la asociación de "Jesucristo" con "Jesupisto". Hay otros casos, por ejemplo en el discurso de la "Iengua de Vaca" en honor del Señor Presidente, se habla de "tenis" en vez de "fénix", de "aquella grora" por "aquella aurora" (p. 98). La confusión de palabras por parte de "la oradora", subraya la intención del autor: hacer una parodia de un pretencioso y vacio discurso político.

Las posibilidades de sugestión por medio de los vocablos son múltiples en la novela. Así, un término puede producir uno u otro sentido, según la situación o el contexto en que se halle. La palabra "pan", por ejemplo, puede significar el alimento $y$, asimismo, puede responder a su acepción onomatopéyica, el golpe de la mano sobre la puerta. Asturias la emplea con ambos sentidos. Esto ocurre en los capítulos ix y Xur en donde la palabra "pan", asociada a Fedina Rodas, suministra el lazo de unión entre una escena en la casa de ésta, a la hora en que llega el panadero, y otra en la casa del general Canales, cuando Fedina golpea a la puerta para prevenirlo de lo que le espera, su capura.

La elaboración de las imágenes también revela la afición de Asturias por la yuxtaposición de perspectivas. En una ocasión el Auditor de Guerra iba "en un carricoche tirado por dos caballos flacos, que llevaba de lum. bre en los faroles los ojos de la muerte" (p. 17). Navas-Ruiz ha llamado la atención sobre esta imagen, indicando que se trata de un procedi. miento "destealizador". Navas-Ruiz indica que "el que ve el coche donde viaja el auditor no sabe si los faroles son luces o los ojos siempre atónitos e inmensos de una calavera".19 Habría que añadir que esta confusión no ocurriría y no tendría ningún significado si no se asociara el carruaje con la figura del Auditor. Es decir, que la relación del carricoche con la muerte alude metafóricamente a la función del Auditor en la dictadura; sólo en términos de esa alusión la imagen adquiere completo sentido.

19 Navas-Ruiz, p. 81. 
La alusión es un recurso de que se sirve Asturias para producir correspondencias y contrastes. La referencia a algo exterior al texto -un libro, un autor, una cita- enriquece, por medio de comparaciones y de identidades, el sentido de la situación descrita. ${ }^{20}$ Durante un día de Fiesta Nacional el pueblo saluda en varias ocasiones al Señor Presidente de esta manera: "¡Señor, Señor, llenos están los cielos y la tierra de vuestra gloria!" (p. 96). El sentido irónico de la frase, en este contexto, surge cuando se recuerda que la cita corresponde a las palabras del "Sanctu", uno de los episodios en la celebración de la misa católica. También con intención irónica aparece el nombre de Juan Montalvo (p. 98). Que los pensamientos del escritor ecuatoriano le sirvan a la "Lengua de Vaca" para enaltecer al Señor Presidente subraya el humorismo de Asturias, especialmente si se tienen presente las luchas del ambateño contra la tiránía teocrática que quiso imponer Gabriel García Moreno en el Ecuador.

Cara de Angel, el prisionero del calabozo número diez y sicte, le pregunta a su compañero de celda, Vich, qué crimen ha cometido contra el Señor Presidente para hallarse "allí donde acaba toda esperanza" (p. 284). Bien puede ocurrir que estas palabras no provoquen ninguna asociación en el lector, en cuyo caso la alusión pasaría inadvertida. Sin embargo, si se la entiende, la alusión cumple la función metafórica de enlazar simultáneamente dos experiencias. En este caso, las palabras de Cara de Angel traen a la memoria, como ha observado Alberto J. Carlos, ${ }^{21}$ las del noveno verso del tercer canto del Inferno de Dante: "Lasciate ogni speranza, voi ch' entrate!" La analogía de la prisión de Cara de Angel con el infierno dantesco se cumple. El paralelo con La Divina Commedia, sugetido por esta alusión, se manifiesta como uno de los más reveladores en cuanto al significado alegótico de El Señor presidente. Invariablemente, Miguel Cara de Angel es descrito como "bello y malo como Satán". Esta descripción halla correspondencias en la obra del florentino. Dante describe a Lucifer de esta manera: ' $S$ ' el fu sì bello com' elli è or brutto" (Inferno XXXIV, 34). Asimismo, Cara de Angel y Lucifer coinciden en "el pecado" de haberse rebelado "contra 'I suo Fattore" (Inferno, XXXIV), 35), Dios y el Señor Presidente respectivamente.

La rebelión, sin embargo, es a la inversa: Lucifer contra las fuerzas

20 Sobre la alusión, véase: Encyclopedia of Poetry and Poetics, ed. Alex Preminger (Princeton, 1965), p. 18; Leo Hickey, "El valor de la alusión en la literatura," Revista de Occidente, XXX, 88 (julio, 1970), 49-60; Ronald Christ, The Narrow Act. Borges' Art of Allusion (New York, 1969), pp. 33-41.

21 "El curioso infierno dantesco en El Señor Presidente," en XIII Congreso Internacional de Literatura Iberoamericana (Caracas, 1968), pp. 78-79. 
del bien, Cara de Angel contra las fuerzas del mal ${ }^{22} \mathrm{La}$ inversión resulta clara si se tiene en cuenta la alusión implícita en el nombre de pila de Cara de Angel: "Miguel". Según la Biblia (Apocalipsis, XII, 7.9), Miguel es el nombre del arcángel que lucha contra el simbólico dragón, Lucifer, y sale triunfante. En un universo donde supuestamente impera el bien, esto resulta perfectamente verosímil. Similarmente, a la inversa, en un mundo en que impera el mal, la dictadura, el ángel - Miguel Cara de Angel- que se rebela contra el dragón -el Señor Presidente-, como era de esperar, sale derrotado.

Además de ilustrar otro aspecto de la preferencia de Asturias por la yuxtaposición de perspectivas, la importancia de estas referencias a $L_{a}$ Divina Commedia y a la Biblia reside en el hecho de que permite leer El Señor Presidente como una alegoría de "la caída", pero al revés: del mal al bien. La novela llega a ser, gracias a los paralelismos y contrastes estimulados por las alusiones, una visión del mundo patas arriba, como en los clásicos adynata. ${ }^{23}$

La yuxtaposición y los contrastes de diferentes niveles de percepción de la realidad también se los observa al nivel de la sintaxis. La esposa de Carvajal, en un momento de desesperación, se acerca a los muros de la cárcel donde cree está encerrado su marido, tratando así, absurdamente, de evitar que una descarga de metralla lo mate. Asturias no describe la descarga, sino que la sugiere por medio de la repetición de ciertas palabras:

Miedo, frío, asco; se sobrepuso a todo por estrecharse a la muralla que repetiría el eco de la descarga. . . Después de todo, ya estando allí, se le hacía imposible que fusilaran a su marido, así como asi; asi, de una descarga, con balas, con armas, hombres como él, gente como él, con ojos, con boca, con manos, con pelo en la cabeza, con uñas en los dedos, con dientes en la boca, con lengua, con galillo... No era posible que lo fusilaran hombres así, gente con el mismo

22 Seymour Menton y Enrique Arenas-Capiello, entre otros, han llamado la atención sobre este particular. Aquí interesa destacar la importancia de la alusión en el método de Asturias.

23 Sobre el adynaton, véase: Ernst Robert Curtius, "The World Upsidedown", en European Literature and the Latin Middle Ages, trad. por William R. Trask' (New York and Evanston, 1963), pp. 94-98; Gustav Rene Hocke, "E1 mundo al revés", en El mundo como laberinto. 1. El manierismo en el arte, trad. por José Rey Aneiros (Madrid, 1961), pp. 297-302; Arnold Hauser, "El Universo puesto al revés," El manierismo, trad. por Felipe González Vicen (Madrid, 1965), pp. 77-79; Encyclopedia of Poetry and Poetics, p. 5; Joseph G. Fucilla, "Petrarchism and the Modern Vogue of the Figure ADYNAToN", Zeitschrift fïr Romanische Pbilologie, LVI (1936), 671-681; Paolo Cherchi, "Gli 'Adynata' Dei Trovatori," Modern Pbilology, LXVIII, 3 (February, 1971), 223-241. 
color de piel, con el mismo acento de voz, con la misma manera de ver, de oír, de acostarse, de levantarse, de amar, de lavarse la cara, de comer, de reír, de andar, con las mismas creencias y las mismas dudas. (p. 219).

La construcción anafórica del texto anterior, subrayada por nuestras letras bastardillas, está sostenida por el adverbio "así" y, particularmenie, por las preposiciones "con" y "de". La repetición rápida de estas dos últimas consigue onomatopéyicamente sugerir el sonido de una descarga de metralla. La asociación y contraste entre los sentimientos de ruego y angustia de la mujer con la violencia de la descarga pasarían totalmente inadvertidos por el lector, a menos que se capte la alusión que intenta el ritmo del idioma.

Finalmente, uno de los pasajes más citados de El Señor Presidente, el viaje en tren de Miguel Cara de Angel, ilustra plenamente muchos de los recursos hasta aquí estudiados: "Seguía... la sensación confusa de ir en el tren, de no ir" en el tren, de irse quedando atrás del tren, cada vez más atrás del tren. . . más atrás del tren, cada vez más atrás. . más y más cada vez, cada ver cada vez. . cada ver cada ver cada ver cada ver cada ver" (pp. 265-266). Más de un crítico ha señalado correciamente que este pasaje es revelador de la gran habilidad lingüística de Asturias. También se ha indicado que esta imagen presagia la futura muerte de Cara de Angel. ${ }^{24}$ Este último juicio interesa aquí, puesto que implica que el significado definitivo de la imagen sólo se lo capta en referencia a detalles futuros de la vida de Cara de Angel. Habría que añadir que para aprehender el sentido de la totalidad de la imagen, es necesario no sólo tener en cuenta incidentes posteriores, sino también incidentes anteriores, imágenes, fragmentos, que sólo vistos en conjun:o, yuxtapuestos, producen el efecto definitivo.

La muerte de Cara de Angel, como una nota en contrapunto, es pre. sagiada desde el primer momento que empieza a enamorarse de Camila: "Camila, él y su pobre amor acababan de volar deshechos en un segun. do... sentía que lo estaban enterrando vivo con los ojos abiertos" (p. 123). En otra ocasión el presagio aparece en la forma de "una es. quela de muerto" (p. 144). También se manifiesta como un "anónimo". que esgrime el Auditor de Guerra (p. 185). Pero no es hasta que Cara de Angel tiene la visión del baile de Tohil, "Dador del fuego" que demanda sacrificios humanos, cuando el presagio se concre'a plenamente. Camila aludirá más tarde a este baile con la intención de justificar sus

24 Menton, ¿. 271 , 
recelos en cuanto a la posibilidad de que el viaje de Cara de Angel al extranjero, en misión especial para el gobierno, resultara ser un engaño: "-Pero con lo que me contabas anoche de los brujos jicaques que bailaban en su casa" (p. 262). Como respuesta a las preocupaciones y miedos de su esposa de que el viaje sea, como resulta ser, un engaño de parte del Señor Presidente, Cara de Angel presagia irónicamente su propio fin: "-_Ya parece que me fuera a morit o me fueran a enierrar vivo!" (p. 263).

Asturias añade a todo lo anterior una escena en la que yuxtapone y contrasta el último coito de Camila y Cara de Angel con el acoso, caza y muerte de un pollo efectuado por las criadas en el patio de la casa. El significado simbólico de esta escena debe ser entendido en términos de la suerte que le espera a Cara de Angel. ${ }^{25}$ La fuga desesperada del pollo es paralela a la fuga de Cara de Angel. Asimismo, la muerte del animal vaticina la futura muerte de Cara de Angel: "Las dos cosas se le sentían en el corazón. . Le retorcieron el pescuezo. .." (p. 264).

El mosaico se cierra con la muerte de Cara de Angel en el calabozo. El méiodo de Asturias ha consistido en ir añadiendo fragmentos al mosaico hasta que, visto en conjunto, produce una imagen amplia y reveladora que informa toda la novela. La imagen educida, por medio de una jerarquía de perspectivas temporales, la metamorfosis de la caída de Cara de Angel y, más importante, también un contraste permanente entre la muerte y el amor, entre la muerte y la ilusión, entre la muerte y la esperanza, entre la muerte y la libertad y entre la muerte y la vida.

Así es que a Asturias le interesa hacer ver que detrás de las apariencias yace escondida una dimensión más profunda de la realidad, aunque no siempre visible en la luz. Así lo destaca la siguiente referencia a los pensamientos del estudiante en la cárcel: "Se deleitaba en sus dolencias físicas para olvidar que había visto la luz en un naufragio, que había visto la luz entre cadáveres, que había abierto los ojos en una escuela sin ventanas, donde al entrar le apagaron la lucecita de la fe $y$, en cambio, no le dieron nada" (p. 200).

El pasaje anterior impone una inversión de perspectivas en la que el orden de las cosas aparece totalmente al revés. Este recurso es utilizado en toda la novela. Ya nos hemos referido, por ejemplo, a la caída del mal al bien de Cara de Angel y al caso de los niños que en vez de llorar

25. Enrique Arenas-Capiello, pp. 244-245, ve esta descripción como un paralelo del acto sexual. Richard Jerome Callan, "El tema del amor y de la fertilidad en El Señor Presidente," Cuadernos Hispanoamericanos, 214 (Madrid, 1967), pp. 202-203, apunta este particular, y además ve esta escena como parte del "ciclo perenne de nacimiento-muerte". 
ríen. Además, importa aquí anotar que en este mundo se celebran sacrificios humanos "para que siga viviendo la muerte" (p. 261). Asimismo, la mayor parte de la acción transcurre en un ambiente en el que "el cementerio es más alegre que la ciudad" (p. 21). Finalmente, para completar la visión del mundo al revés, se da el caso de la figura de Cristo agachada ante el Señor Presidente:

Jesús pasó vencido bajo el peso del madero frente al César y al César se volvieron admirados hombres y mujeres. No fue mucho el sufrir, no fue mucho el llorar hora tras hora, no fue mucho el que familias y ciudades envejecieran de pena; para aumentar el escarnio era preciso que a los ojos del Señor Presidente cruzara la imagen de Cristo en agonía y pasó con los ojos nublados bajo un palio de oro que era infamia, entre filas de monigotes, al re. doble de músicas paganas. (p. 217).

\section{IX}

Resumiendo, en este estudio hemos puesto de relieve la función e importancia de los paralelismos, de los contrastes, de la analogía, de los desdoblamientos, de los símbolos, de las máscaras, de la teatralidad, de la parodia, de lo grotesco, de la paronomasia, de la sintaxis, de la imagen y del adynaton en la elaboración artística de El Señor Presidente. Todos estos recursos subrayan la afición de Asturias hacia una visión estereos. cópica de la realidad. Asimismo, esos recursos demuestran que el método en que organiza la novela consiste fundamentalmente en el montaje de perspectivas contrastantes. ${ }^{26}$ Dentro de este procedimiento el desajuste entre las situaciones yuxtapuestas produce el mensaje y la intención ética de la novela. Esta intención, cuya presencia es constante e invariable en la narrativa, permite decir del autor guatemalteco algo parecido a lo que Leo Spitzer dijo sobre Cervantes, que "en cuanto moralista... no es en absoluto 'perspectivista" ". ${ }^{27}$

Humberto E. Robles

\section{Northwestern University}

26 Ahora vale traer a colación los juicios de Arnold Hauser sobre la técnica del montaje y su relación con el surrealismo: "La esencia del montaje consiste en la relación directa de elementos heterogéneos de la obra, y en este sentido, la técnica del montaje cinematográfico contiene el principio formal de todo el surrealismo, e incluso de todo el nuevo arte" (p. 402).

27 "Perspectivismo lingǘstico en El Quijote," en Lingüistica e bistoria lite. rariat, 2a. ed. (Madrid, 1961). p. 186. 